\title{
SOBRE OS ESTUDOS EM MASCULINIDADES NO BRASIL: REVISITANDO O CAMPO
}

\author{
Karla Galvão Adrião ${ }^{1,2}$
}

\section{A CONSTITUIÇÃO DE UM CAMPO}

Estamos no início da década de 90 no Brasil, quando acontece um boom de estudos sobre o masculino nos diversos centros acadêmicos. Para compreendermos este momento e os subseqüentes, faremos esta viagem no tempo, buscando encontrar os primeiros trabalhos sobre masculinidades e a constituição deste campo de estudo. Tenhamos em conta que estamos na seara dos estudos feministas. As discussões sobre a condição feminina, tomando o recorte do Brasil ditadura e pós-ditadura, situam-se nos espaços de militância, e consolidam-se na academia. Núcleos de estudos sobre as mulheres são criados em diversas universidades no País. Ainda na década de 80 , os estudos feministas começam a lidar com a noção relacional de gênero, que passava a discutir as desigualdades entre homens e mulheres desde uma perspectiva do poder nas relações. E, é após a inserção do campo de estudos sobre gênero, que surgem os primeiros trabalhos inseridos em uma temática que seria chamada por muitos/as pesquisadores/as da época de "estudos sobre masculinidades".

A noção de gênero, ao tratar dos aspectos relacionais, permitia visibilizar mais este outro, a saber, o homem, na discussão sobre a condição da mulher na sociedade, em suas micro e macrorrelações. E, ao tratar os homens neste contexto, permitiu a criação deste campo de estudos que se constituiu como estudos sobre as masculinidades. Assim, nas décadas de 60, estudos sobre os homens surgem e, nas décadas de 80 e 90, se consolidam e começam a dialogar com os estudos de gênero existentes. Nesta época surgiram diversos trabalhos nos Estados Unidos e na Europa, localizados principalmente na Psicologia, Antropologia e História Social (HEILBORN e CARRARA, 1998). Estes estudos baseavam-se na tese de que havia necessidade de compreender melhor as masculinidades, as especificidades sobre o ethos masculino, assim como havia sido feito com os estudos sobre as mulheres nas décadas anteriores.

Em alguma medida, o desenvolvimento desta área vem cumprindo a função de falar dos homens em uma perspectiva que não vinha sendo tratada, ou seja, relacional. Como um campo que está se constituindo, apresenta, por

1 Doutoranda do programa Interdisciplinar em Ciências Humanas - DICH/UFSC. Sob orientação da prof. Dr $r^{\mathrm{a}}$ Miriam Pilar Grossi e co-orientação da prof ${ }^{\mathrm{a}} \mathrm{Dr}^{\mathrm{a}}$. Juracy Toneli, pesquisadora dos núcleos NIGS (Núcleo de Identidades de Gênero e Subjetividades/Núcleo de Famíla e Gênero) UFSC, Instituto Papai/Recife.

2 Contribuiram muito para a construção deste texto os colegas da disciplina da Pós-graduação em Psicologia da UFSC, "Psicologia e Estudos de Gênero", mais especialmente Adriano Beiras, com quem dialoguei diretamente e que me trouxe importantes reflexões. 
um lado, estudos que partem da problematização da chamada "crise do masculino" sob o olhar e a perspectiva das relações de gênero e, por outro, estudos que buscam tratar das várias possibilidades de se falar do masculino, em seus diversos sentidos constituídos. Estes estudos que problematizam a "crise" do masculino, da identidade masculina, surgiram por volta dos anos 60 , influenciados pela segunda vaga feminista e pelo movimento homossexual, mas se constituíram como campo consolidado por volta dos anos 90 (HEILBORN e CARRARA, 1998).

É importante salientar que estamos trabalhando com a área de estudos sobre as masculinidades desde uma perspectiva de autores e autoras que se utilizam do gênero como uma categoria de análise, e buscam, assim, sair das armadilhas de uma vitimização do masculino e dos homens, para uma análise que traga conhecimento sobre as particularidades que permeiam as construções das masculinidades e, como a compreensão destas realidades pode auxiliar nas ações de eqüidade nas relações de gênero. No início dos anos 90, grandes conferências internacionais (Beijing e Cairo) enfatizaram a necessidade de incorporar os homens como alvos de políticas de implementação de uma maior eqüidade entre os sexos, enfatizando a necessidade de ações na população masculina ${ }^{3}$.

No Brasil, o campo de estudos sobre masculinidades inicia-se com algumas teses de mestrado, realizadas no Sudeste e no Sul do Brasil, na década de 90. Estes estudos situam-se em áreas como Antropologia (UFSC) e Psicologia Social (PUC-SP); vêm lançar olhares sobre o homem moderno, jovem e de meia-idade, e suas relações com afetos, com o trabalho, com as mulheres, com seus corpos, com a reprodução e com a sexualidade. Tratavam de compreender as angústias destes homens e como estes constituíam suas subjetividades, por um lado, e, por outro, como certas normas e valores impostos aos homens no convívio social levavam estes a serem mais ou menos responsáveis em relação às mulheres e aos avanços feministas. Margareth Arilha (1998), por exemplo, tratava de estudar sobre homens jovens que, diante da paternidade na adolescência, se consideravam mais responsáveis e "transformavam" sua forma de lidar com o mundo, saindo de um mundo jovem e sem tantos deveres, para outro adulto, em que o homem era aceito e valorado pela sua capacidade de ser provedor. Em um outro caminho, Roseli Buffon (1992) realiza uma etnografia sobre o homem sensível, uma parcela de homens de camadas médias, com idade média de 30 anos, que realizavam afazeres domésticos, eram em sua maioria solteiros; cozinhavam, faziam grandes pratos, tinham a casa organizada, e valorizavam estes dotes, como algo que dava a eles poder e prestígio.

$\mathrm{Na}$ América Latina, tivemos diversos trabalhos realizados sobre homens jovens, paternidade e reprodução, dentre outros, por pesquisadores/as tais como: José Olavarria e Tereza Valdes, na Faculdade

3 Uma crítica aos estudos sobre masculinidades era que justamente estes estudos faziam uma inversão no campo - de estudos sobre mulheres para estudos sobre homens - sem considerarem que as desigualdades existentes são caracterizadas e só podem ser minimizadas se trabalhamos com uma perspectiva relacional para compreensão dos fenômenos sociais (COSTA, 2002). 
FLACSO, no Chile; Norma Fuller, na Universidade Católica de Lima, no Peru; Juan Guillermo Figueroa, na Universidade Aberta do México, etc. Alguns/as destes/as pesquisadores/as realizaram atividades em conjunto com pesquisadoras feministas brasileiras (ênfase para Albertina Costa, da Fundação Carlos Chagas, com o programa de bolsas para pesquisas e intervenções sobre gênero e, alguns anos mais tarde, sobre masculinidades), consolidando um campo de estudos de gênero e, mais tarde, especificamente sobre masculinidades.

No campo de estudos sobre as masculinidades (CONNELL, 1995; KIMMELL, 1997; ALMEIDA, 1995 e 1996; entre outros), há, de certa maneira, um consenso com relação a um modelo de masculinidade que enquadra os homens e os leva a buscar alcançá-lo. Para alguns destes autores, este seria um modelo de masculinidade hegemônica, ideal e totalizante. O homem ideal, se pudesse ter uma cara, seria branco, ocidental, de classe dominante, provedor, heterossexual, forte e viril (KIMMELL, 1997). Marcas do homem machista e forte, que põe o dinheiro em casa, que tem o trabalho como maior referência, em que a família e os trabalhos reprodutivos não são prioritários, que, por ser tão forte e voltado para o mundo publico (e não o privado), não cuida dos outros e outras, nem de si próprio, adoecendo, não se prevenindo de DST/HIV/AIDS, etc.

Miguel Vale de Almeida, antropólogo português, em seu conhecido estudo "Senhores de Si" (1995), traz os vários retratos de uma comunidade, uma vila de Portugal, mapeando as diversas formas de lidar com o mundo, vivenciadas pelos homens nas suas relações com outros homens e com outras mulheres. Nesta mesma direção, Pedro Nascimento (1999), em sua dissertação de mestrado em antropologia pela UFPE, trabalhou com homens que não tinham emprego e viviam à margem em uma comunidade de classe popular. Interessante acompanhar as relações de poder que construíam a partir de um modelo binário do que significa ser homem ou ser mulher em nossa sociedade: como esses homens, que eram sustentados por outras mulheres (mãe, irmã, esposa, etc.) e viviam bebendo quase todo o dia, reproduziam ou não o modelo ideal de ser homem, conviviam com os outros homens e com as mulheres.

\section{PROBLEMATIZANDO O CAMPO: CRÍTICAS FEMINISTAS}

Caminhando mais na busca de compreensão dos estudos de gênero, é interessante observarmos 0 argumento trazido por Rosely Costa, em seu artigo "Mediando oposições: sobre as críticas aos estudos de masculinidades" (2002). A autora cita dois aspectos trazidos por diversos teóricos e teóricas, com relação aos estudos de masculinidades. De uma forma geral, o que encontram autores como Sahlins (1979, citado em COSTA, 2002) é que os estudos sobre mulheres são marcados pelo sexo/gênero, enquanto que os homens têm aparecido em estudos como não-marcados por esta mesma relação. Costa acrescenta que os homens precisam ser estudados como marcados, sob pena de desconhecimento de suas especificidades de gênero. $\mathrm{E}$ as mulheres precisam ser estudadas como não-marcadas, sob pena de 
serem estigmatizadas pelo seu (segundo) sexo (2002, p. 225).

Piscitelli (1997), ao tratar dos estudos sobre masculinidades, acrescenta que não faz sentido a ênfase em um dos lados da categoria de gênero. Costa (2002), sobre este mesmo tema, comenta que o importante é manter a análise relacional, não enfatizando nem homens nem mulheres.

Outra crítica apontada por Costa, à semelhança de Corrêa (2002), seria a de que estudos sobre masculinidades retirariam a força política das mulheres, já que um outro campo de estudos, em oposição aos estudos sobre mulheres, estaria se formando. Esta análise já é bastante rebatida, inclusive pela própria autora, que coloca a necessidade de se realizar estudos sobre homens e mulheres, tomando as relações de gênero como aporte teórico.

Entretanto, no debate entre teoria e prática, nos vemos diante de uma tensão, em que o lugar dos homens nas ações do movimento feministas se coloca entre momentos de parceria e de divisão de espaços. Ou seja, a participação dos homens apresenta-se como uma questão incômoda porque se encontra sem respostas conclusivas. Por outro lado, demonstra um momento em que o feminismo no Brasil se depara com outras questões, pensando em vários modelos de homens e não mais em um único: dominante e opressor; embora esta condição de desigualdade permaneça, de uma forma geral, ainda colada à divisão sexual (em contraposição, inclusive, a discussões teóricas que desconstroem o gênero).

Preocupações como esta, colocada acima, demonstram um pouco deste incômodo que, muitas vezes, acompanha o lugar do masculino para os estudos feministas. Strathern (1987), tratando da relação entre Antropologia e feminismo, considera que é importante para a construção do self feminista um outro não-feminista. Geralmente, esse outro é o patriarcado, as instituições e pessoas que representam a dominação masculina: os "homens". Então, se por um lado, o masculino está sempre presente como o outro desta relação binária, que caminhos são traçados a partir desta dicotomia que aparece na base das discussões feministas?

Neste sentido, o texto de Linda Nicholson, "Interpretando o gênero", da Revista Estudos Femininistas, de 2000, traz algumas luzes. Vejamos: neste artigo, a autora preocupa-se em trabalhar questões bastante pertinentes ao Estado da Arte Feminista. Noções sobre corpo e suas implicações para as construções de sexo e gênero. As inscrições sobre o que é ser homem e ser mulher tratam do próprio lócus de ação feminista, e de uma construção de identidade sobre ser mulher que deve ser analisada mais pormenorizadamente. E, é isto exatamente o que Nicholson vai fazer.

Inicia mostrando que, ao lidar com "Gênero", existem dois caminhos epistemológicos trilhados, que podem ser assim descritos: 1. gênero em oposição a sexo, para descrever o que é socialmente construído, em oposição ao que é biologicamente dado. Neste caso gênero e sexo são distintos e; 2 . Gênero como referência a qualquer construção social que tenha a ver com a distinção masculino/feminino, incluindo as construções que separam corpos "femininos" de corpos "masculinos". A autora diz que, apesar desse segundo sentido ter prevalecido no discurso feminista, ainda assim, a herança do primeiro subsiste. "O sexo permanece na teoria feminista como aquilo que fica de fora da cultura e da história, sempre a enquadrar a diferença 
masculino/feminino" (NICHOLSON, 2000, p.10).

Em meados dos anos 60, o termo gênero ainda era usado principalmente como referência a formas femininas e masculinas dentro da linguagem. Não como substituto para sexo, mas como meio de minar as pretensões de abrangência do sexo: "fenômenos biológicos reais a diferenciar mulheres de homens". Não só o gênero não era visto como substituto de sexo, como também sexo parecia essencial à elaboração do próprio conceito de gênero. Sexo aparecia como provedor de um lugar no qual o gênero seria supostamente construído ${ }^{4}$. Há críticas da autora com relação a estas visões, que, segundo ela, não permitem perceber as diferenças entre homens e mulheres e a quem pode ser considerado homem ou mulher. Neste sentido, o corpo é tomado para criar generalizações sobre mulheres, mas o feminismo da diferença vai se constituir como um feminismo da uniformidade, determinando o que as mulheres são, na medida em que as diferenciam dos homens (NICHOLSON, 2000).

Neste sentido, a dicotomia entre duas noções aparentemente antagônicas - homem e mulher - continua sendo acentuada. Neste caminho, feministas continuam discutindo, por um lado, sobre como sair das ciladas dicotômicas, buscando um conceito de gênero que trabalhe com a flutuação do feminino e do masculino, sobre corpos (aos moldes de BUTLER, 2003). Retirando, assim, da pré-condição biológica do sexo (como algo dado e não construído), que vai dizer se somos homens - portanto da ordem do masculino - ou mulheres - da ordem do feminino - como algo a priori, que nos constitui enquanto sujeitos/as.

Nestes percalços, os estudos sobre homens, enquadrados em um campo nomeado muitas vezes como de "Estudos de Masculinidades", podem ser destacados como um contraponto interessante ao destacar as questões da ordem do masculino. Por outro lado, há que ter cuidado com os caminhos trilhados, de forma tal que não se reforce uma dicotomia às avessas: saindo dos estudos sobre mulheres para os estudos sobre homens.

\section{INSTITUIÇÕES DA SOCIEDADE CIVIL E O CAMPO DE ESTUDOS E INTERVENÇÕES COM HOMENS}

Trabalhando com a perspectiva feminista e de gênero há cinco anos, o

4 Tratando de nomear estes dois caminhos, um destes, o determinismo biológico, vai descrever e situar o gênero a partir da premissa de que: as constantes da natureza são responsáveis por certas constantes sociais. Este caminho permitiu às feministas da segunda geração, que dele se apropriaram como modelo explicativo, assumir tanto as diferenças entre as mulheres, quanto o que elas tem em comum. Segundo esta vertente, os dados da biologia podem coexistir com os aspectos da personalidade e do comportamento. Algumas premissas: a) ainda há alguns dados biológicos presentes em todas as culturas, que distinguem mulheres de homens; $b$ ) acreditam na existência de aspectos comuns a várias culturas, e; c) concordam com o construcionismo social (a sociedade tem participação num determinado resultado).

Entretanto, percebeu-se, depois, que as diferenças entre as mulheres não podiam ser bem trabalhadas neste paradigma. E havia, cada vez mais, necessidade de serem colocadas as particularidades, através de ligações com raça/etnia, classe, geração etc. Então, o que a autora vai chamar de "Fundacionalismo Biológico"aparece como alternativa epistemológica. 
Instituto PAPAI, ONG situada em Recife-PE, vem desenvolvendo pesquisas, intervenção social e formação, tomando os homens como público-alvo de suas ações. A partir de estudos de gênero, e problematizando as questões de saúde e direitos sexuais e reprodutivos, um diálogo junto a diversos atores da sociedade vem sendo travado no sentido de trazer os homens para refletirem sobre arenas da reprodução, da vida privada, questionando ações pautadas no machismo e que tởmam como base a socialização de meninos e meninas para agirem sob esta ou aquela situação, de forma tal que se alargue ou não a desigualdade de gênero. Outras experiências, tais como a do Instituto Promundo, no Rio de Janeiro, da ECOS, em São Paulo, e do Salud \& Genero, no México, vem, de forma semelhante, problematizando esta área de ação e construindo perspectivas de atuar junto aos homens, a partir das relações de gênero. Siqueira (2000) coloca que a exclusão da figura masculina das investigações, e também de trabalhos teóricos, constitui-se como uma lacuna grave que já começa a ser preenchida. Esta mesma autora diz que se trata de uma questão de ordem ético-política, o fato de os homens serem tematizados e abordados como sujeitos de direito e de fato, e participantes ativos na negociação cotidiana da vida sexual e reprodutiva e, também, nas agências que são responsáveis pela produção e socialização do conhecimento e pelas políticas publicas nesta área.

Pesquisas realizadas pelo Instituto Noos e Promundo (ACOSTA, 2003) junto a homens jovens de classe popular, no Rio de Janeiro, vêm falar um pouco da questão da violência e de como esta é vivenciada por estes atores. Num mesmo caminho, a campanha do laço branco - homens pelo fim da violência contra a mulher, vem discutindo junto a homens a importância de não silenciar frente à violência praticada contra as mulheres. Estas ações têm impactos que relatam, por um lado, a possibilidade dos homens em resignificarem ações tais como a resolução de conflitos de forma violenta, sem, com isso, se sentirem menos ou mais homens; por outro lado, recebem do movimento feminista acolhida, no sentido de estarem atuando em prol da qualidade de vida das mulheres.

Por outro lado, a forma como as pessoas que trabalham com homens relacionam suas reflexões e ações a uma perspectiva feminista está distante de ser uma prática homogênea. Problematizar as ações realizadas junto aos homens de forma tal a tratá-las a partir de parâmetros relacionais é uma questão que se coloca por feministas, de um lado, e pelas próprias instituições de outro. O diálogo existente fala, porém, de que tipo de aberturas? É possível trabalhar com homens pelas próprias necessidades do campo - as violências simbólicas sofridas por homens, ademais destes estarem em posição de opressão? Ou, é necessário discutirmos este campo a partir da qualidade de vida para as mulheres? Ou, estas duas questões, já trazidas anteriormente neste texto, se colocam de maneira dicotômica e cristalizada? 


\section{OS ESTUDOS SOBRE AS MASCULINIDADES: O SEMINÁRIO \\ INTERNACIONAL SOBRE HOMENS, SEXUALIDADE E \\ REPRODUÇÃO, NO BRASIL, EM 2003}

Pensando no campo que ora se constitui e na influência deste nos estudos feministas e vice-versa, foi construído o II Seminário Internacional sobre Homens, Sexualidade e Reprodução, em junho de 2003, com participação de estudiosas e estudiosos em feminismo e gênero que estão, de alguma maneira, particularmente interessados/as em estudar e pensar sobre as masculinidades. Na ocasião, na mesa de abertura, foram chamados a incitarem a reflexão de todos participantes uma feminista histórica - Betânia Ávila - e um homem estudioso da área, que vem, a convite de algumas feministas brasileiras, pensando sobre estas questões, a saber, do masculino nos estudos de gênero - Juan Guillermo Figueroa, do Colégio de México.

Os dois trataram de pensar sobre os estudos de masculinidades. A primeira trouxe reflexões sobre a participação masculina e o lugar do masculino nos estudos feministas. Ávila falava que a questão não era incluir os homens, mas transformá-los. Figueroa, por sua vez, colocou, dentre outras coisas, que o que sabemos sobre os homens, este objeto de estudo que ora se constitui, pode estar alocado dentro de sentimentos do senso comum, para o qual, saber do que os homens pensam e como agem é algo já datado. Porém, o autor nos chama a pensar a própria formação de um objeto de estudo, ou seja, quando se fala de masculinidade e de jovens, é óbvio o objeto de estudo em termos da masculinidade? Este contraponto ele fazia em relação á necessidade de um diálogo sem busca de verdades absolutas, entre os estudos feministas e o lugar esperado que os homens ocupem em nossa sociedade, a saber, um lugar de transformação de desigualdades em equidade nas relações de gênero.

Citando alguns exemplos de trabalhos com homens existentes, Figueroa coloca que, por um lado, estes vêm responder a expectativas de comportamentos esperados, dentro de uma sociedade específica, que os homens jovens correspondam. Algumas vezes, estes sentidos podem estar indo a uma direção maniqueísta e normativa, que coloca uma oposição entre homens jovens maus que devem ser transformados. Outra leitura trata de trabalhar com a responsabilização dos homens em espaços que estes se tornam omissos, como o da reprodução, por exemplo. Então, o autor nos chama, mais uma vez, a pensarmos sobre questões que, aparentemente possam parecer dadas e datadas, buscando fazer um caminho onde devemos nos indagar sobre cada obviedade: como se constitui e em que nos vemos nessa relação com o objeto de estudo. Trabalhar em termos relacionais e levar em consideração a construção de novas linguagens, de forma a nomear novas realidades, parece ser um possível caminho, aponta ele.

\section{CONSTITUIÇÃO DAS MASCULINIDADES}

Assim como Connell (1995), Kimmell (1997), dentre outros, Daniel Welzer-Lang (2001), pesquisador francês que se dedica aos estudos sobre 
masculinidades, faz um interessante paralelo entre violências, homofobia e sexualidade (trabalhando bastante com teorias queer). Em seu texto, "A construção do masculino: dominação das mulheres e homofobia” (2001), o autor traz importantes questões, relacionando masculinidades e feminismo, e as constituições de subjetividades masculinas. Abaixo, trazemos alguns pontos que julgamos interessantes para este debate:

Segundo o autor, existem diversas constituições de homens (drags, travestis, etc.) Os modelos e as reivindicações destes homens expõem uma variedade extrema, mas eles têm em comum o fato de colocar objetivamente e/ou que existe uma pseudonatureza superior do homem, que remete a dominação masculina. Outros pontos, já trazidos anteriormente nas aulas desta disciplina são salientados pelo autor:

- que existe uma visão heteronormativa do mundo e da sexualidade;

- que as desigualdades vividas pelas mulheres são efeito das vantagens dadas aos homens.

Para Welzer-Lang (2001), assim como para Connell (1995), Kimmell (1997), Kauffman (1997), entre outros, o gênero mantém-se e é definido e regulado por violências. Isto tende a manter os poderes que se atribuem coletivamente e individualmente aos homens a custa das mulheres. Assim, a dominação masculina e as relações homens/homens são marcadas por violências, simbólicas e concretas, a despeito de pesquisas de Godelier (citado em WELZER-LANG, 2001) com sociedades primitivas sobre a casa dos homens-rituais de passagem para construir o fortalecimento dos homens em detrimento das mulheres. Rituais com esperma, sexualização, rituais iniciáticos. Fazendo um paralelo destes rituais com as sociedades complexas, Welzer-Lang vai dizer que aprender a sofrer é norma para ser homem. Aceitando as leis dos maiores, os que detêm a dominação, os homens que são poderosos e que oprimem outros homens e outras mulheres, é que se constituem as identidades masculinas. Assim, para ser homem é preciso se distanciar do oposto, ou seja, das mulheres e das crianças. Para ser homem não se pode ser associado à mulher. O feminino se torna o pólo de rejeição central, o inimigo interior que deve ser combatido sob pena de também ser assimilado a uma mulher e também ser (mal)tratado como tal. Diz o autor que apreende-se a sexualidade masculina através desta iniciação, a partir dos prazeres de se estar entre homens e se distinguindo das mulheres.

Continuando, os homens em relação uns aos outros se regulam através da dominação, que produz homofobia. Isto se dá para que, com ameaças, os homens se calquem sobre os esquemas ditos normais da virilidade. Neste sentido, mesmo sendo um homem, um grande homem, todo homem está também submetido as hierarquias masculinas. Neste duplo poder, vão aparecer homens que têm poder sobre homens e sobre mulheres, se estruturando, assim, as hierarquias masculinas ${ }^{5}$.

5 Na França, dois modelos: por um lado em volta das correntes feministas, que privilegiam a analise das relações sociais de sexo e a dominação masculina. Por outros escritos inspirados em Foucault, de historiadores com Áries, que pōem em suspeição o quadro heterossexuado da normatividade masculina (WELZER-LANG, 2001, p. 467). 
O autor chama a atenção para a dominação que se apresenta de forma velada na contemporaneidade, pois, segundo ele, houve uma transformação do masculino como gênero, a partir da contestação da supremacia masculina pelas feministas. Isto provocou mudanças na sociedade contemporânea sim, porém, alerta Welzer-Lang, que a dominação masculina perdura, mas tendencialmente se pulveriza e perde sua acuidade opressiva.

Ao mesmo tempo, o gênero masculino se modifica, integra outros conteúdos, outros valores. O que não quer dizer que não tenha havido recomposição da dominação masculina, e que a colocação em dúvida da masculinidade seja linear ou que seja necessário esquecer a articulação entre relações sociais de sexo e estruturação em classes sociais. Um dos motivos para que haja essa diluição, diz o autor, é porque o masculino é menos perceptível que o feminino na medida em que o primeiro pode mais facilmente disfarçar-se de interesse geral: os conteúdos culturais completamente neutros em aparência mascaram a essência do masculino. Além disso, não se sabe se existe uma categoria homem, pois se trata apenas do masculino como um todo, e não em suas particularidades, nas diversas masculinidades constituintes.

Concluindo, diz o autor que devemos mudar nossos paradigmas críticos, pelo menos aceitar que se juntem analises anti-sexistas e não heteronormativas, pois este caminho oferece instrumentos para descobrir nossas representações unívocas, e muito freqüentemente uniformes, dos homens e do masculino. A ESCUTA DOS HOMENS E DE MULHERES QUE HOJE VIVEM, ENCENAM OU SUGEREM OUTROS TIPOS DE SEXUALIDADE E DE GÊNERO CONTRIBUI PARA ISTO (WELZER-LANG, 2001).

$E$, é esta a contribuição maior, penso eu, que pode estimular mais e mais o debate, e promover a ampliação do campo de estudos.

\section{REFERÊNCIAS BIBLIOGRÁFICAS}

ACOSTA, Fernando. Homens, violência de gênero e saúde sexual e reprodutiva: um estudo sobre homens no Rio de Janeiro/Brasil. Rio de Janeiro: Instituto NOOS, 2003.

ALMEIDA, Miguel Vale de. Senhores de si: uma interpretação antropológica da masculinidade. Lisboa: Fim de Século, 1995.

ALMEIDA, Miguel Vale de. Gênero, masculinidade e poder: revendo um caso do sul de Portugal. Anuário Antropológico/95. Rio de Janeiro: Tempo Brasileiro, 1996.

ARILHA, Margareth, RIDENTI, Sandra G. U. e MEDRADO, Benedito (orgs.). Homens e masculinidades: outras palavras. São Paulo: ECCOS/Editora 34, 1998.

BUFFON, Roseli. Encontrando o homen sensivel?: reconstruções da imagem masculina em um grupo de camadas médias intelectualizadas. Dissertação (Mestrado). Florianópolis, UFSC, 1992.

BUTLER, Judith. Problemas de gênero: feminismo e subversão da identidade. Rio de Janeiro: Civilização Brasileira, série Sujeito e História, 2003.

CONNELL, R. Masculinities. Berkeley: University of California Press, 1995.

CORREAA, Mariza. Prefácio de Gênero em Matizes. In: ALMEIDA et Alii (orgs). Gênero em matizes. Estudos CDAPH. Série História e Ciências Sociais. Bragança Paulista: EDUSF, 2002.

COSTA, Rosely. Mediando Oposições: sobre as críticas aos estudos de masculinidades. In: ALMEIDA et Alli (orgs).Gênero em matizes. Estudos CDAPH. Série História e Ciências Sociais. Bragança Paulista: EDUSF, 2002.

HEILBORN, M. L. e CARRARA. Em cena, os homens... Revista Estudos Feministas, Florianópolis, vol. 6, ํㅜㄹ 2, 1998. 
KAUFMAN, Michael. Las experiencias contradictorias del poder entre los hombres. In: VALDÉS, Tereza y OLAVARRIA, José (eds.) Masculinidad/es. Santiago: FLACSO/ISIS Internacional, Ediciones de las Mujeres, 1997. p. $63-81$.

KIMMELL, Michael S. Homofobia, temor, vergüenza y silencio em la identidad masculina. In: VALDES, T. e OLAVARRÍA, J. (orgs.). Masculinidade. Santiago: Isis Internacional; FLACSO Chile, 1997. p. 49-62.

NASCIMENTO, Pedro F. G. do. "Ser homem ou nada": diversidade de experiências e estratégias de atualização do modelo hegemônico da masculinidade em Camaragibe/PE. 1999. 106p. Dissertação (Mestrado em Antropologia Cultural), Departamento de Ciências Sociais, Universidade Federal de Pernambuco, Recife, 1999.

NICHOLSON, Linda. Interpretando o gênero. Revista Estudos Feministas, Florianópolis, vol. 8, $n^{\circ}$ 2, 2000.

PISCITELLI, Adriana. Ambivalência sobre os conceitos de sexo e gênero na produção de algumas teóricas feministas. In: Aguiar, Neuma (org) Gênero e Ciências Humanas: desafio às ciências desde a perspectiva das mulheres. Rio de Janeiro: Rosa dos Tempos, 1997. p. $49-66$.

SIQUEIRA, Maria Juracy Tonelli. Saúde e direitos reprodutivos: o que os homens têm a ver com isso? Revista Estudos Feministas, Florianópolis, vol. 8, no 1, 2000.

STRATHERN, Marilyn. The gender of the gift: problems with women and problems with society in Melanesia. Berkeley: University of California Press, 1987.

WELZER-LANG, Daniel. A construção do masculino: dominação das mulheres e homofobia. Revista Estudos Feministas, Florianópolis, vol. 9, n. 2, 2001.

\section{BIBLIOGRAFIA EM MASCULINIDADES}

ALMEIDA, et alii. Gênero em matizes. Estudos CDAPH. Série História e Ciências Sociais. Bragança Paulista: EDUSF, 2002.

Anuário antropológico 95. Rio de Janeiro: Tempo Brasileiro, 1996.

BADINTER, Elisabeth. XY: sobre a identidade masculina. Rio de Janeiro: Nova Fronteira, 1993.

BOURDIEU, Pierre. O sentimento de honra na sociedade Cabila. In: Honra e vergonha, valores de sociedades mediterrrâneas. Lisboa: Fundação Calouste Gulbenkian, 1988.

BOURDIEU, Pierre. A dominação masculina. Rio de Janeiro: Bertrand Brasil, 1999.

BOZON, Michel. Sexualidade e conjugalidade: as reformulações das relações de gênero. Cadernos Pagu, Campinas, n. 20, 2003, p. 131 - 156.

CALDAS, D. (org) Homens: comportamento, sexualidade, mudança. São Paulo: Editora Senac, 1997.

CONNELL, R. W. La organización social de la masculinidad. In: VALDÉS, Tereza y OLAVARRIA, José (eds.) Masculinidad/es. Santiago: FLACSO/ISIS Internacional, Ediciones de las Mujeres, 1997. p. $31-48$

CONNELL, R. W. El imperialismo y el cuerpo de los hombres. In: VALDÉS, Teresa y OLAVARRÍA, José (eds.) Masculinidades y equidad de género en America Latina. Santiago: FLACSO, 1998. p. 76 - 89.

DOS SANTOS, Bernardette Grossi. O reino da impura sorte: mulheres e homens, garimpeiros em Minas Gerais. 2001. Dissertação de Mestrado, PPGAS/UFSC, 2001. Acervo NIGS.

FONSECA, Cláudia. Cavalo amarrado também pasta. In: RBCS, n.15, 1991.

FULLER, Norma. Reflexiones sobre el machismo en América Latina. In: VALDÉS, Teresa y OLAVARRIA, José (eds.) Masculinidades y equidad de género en America Latina. Santiago: FLACSO, 1998. p. 258 - 266.

FULLER, Norma. Paternidades en America Latina. Lima: Fondo Editorial Pontificia Universidad Católica del Peru, 2000. 
FULLER, Norma. Identidades masculinas. Lima: Fondo Editorial Pontificia Universidad Católica del Peru, 1997.

FULLER, Norma. Masculinidades: cambios y permanencias. Lima: Fondo Editorial Pontificia Universidad Católica del Peru, 2001.

GARCIA, Sandra M. Conhecer os homens a partir do gênero e para além do gênero. In: ARILHA, Margareth, RIDENTI, Sandra G. U. e MEDRADO, Benedito (orgs.). Homens e masculinidades: outras palavras. São Paulo: ECCOS/Editora 34, 1998. p. 31 - 50.

GROSSI, Miriam. Gênero e parentesco: famílias gays e lésbicas no Brasil. Cadernos Pagu, Campinas, n. 21, 2003. p. $261-280$.

GROSSI, Miriam. "Rimando amor com dor": reflexões sobre a violência no vínculo afetivo-conjugal". In: Masculino, Feminino e Plural. Florianópolis: Mulheres, 1998.

HÉRITIER, Françoise. Masculino e Feminino. In: Enciclopédia Einaudi na BU, 1989.

HURSTEL, Françoise. As novas fronteiras da paternidade. Campinas, Papirus, 1999.

KIMMEL, Michael S. El desarrollo (de género) del subdesarrollo (de género): la producción simultánea de masculinidades hegemónicas y dependientes en Europa y Estados Unidos. In: VALDÉS, Teresa y OLAVARRÍA, José (eds.). Masculinidades y equidad de género en America Latina. Santiago: FLACSO, 1998. p. 207 - 217.

KIMMELL, Michael S. Homofobia, temor, vergüenza y silencio en la identidad masculina. In: VALDÉS, Tereza y OLAVARRÍA, José (eds.) Masculinidad/es. Santiago: FLACSO/ISIS Internacional, Ediciones de las Mujeres, 1997. p. 49 - 62.

KIMMELL, Michael S. A produção simultânea de masculinidades hegemônicas e subalternas. In: Horizontes Antropológicos, Porto Alegre, ano 4, outubro de 1998.

LEAL, Ondina Fachel et al. Insultos, queixas, sedução e sexualidade: fragmentos de identidade masculina em uma perspectiva relacional. In: Sexualidades Brasileiras. Rio de Janeiro: Relume Dumará, 1996.

MENDES, Juliana Cavilha. Histórias de quartel: Um estudo de masculinidades com oficiais fora da ativa. Dissertação de Mestrado, PPGAS/UFSC, Acervo NIGS, 2001.

MOTTA, Flávia de Mattos. Bem mulherzinha: o sexo, o corpo e a relação homem/mulher. In: Velha é a vovozinha: Identidade feminina na velhice. Santa Cruz do Sul: Edunisc, 1998.

MOTTA, Flávia de Mattos. Curió valente: representações de gênero em competições de pássaros canoros, artigo exposto na V RAM, 2003.

OLAVARRÍA, José. ?Hombres a la deriva? Chile: FLACSO, 2001.

OLAVARRÍA, José. Hombres; identidad/es y violência. Chile:FLACSO, 2001.

OLAVARRÍA, José. Hombres: identidad/es y sexualidad/es. Chile:FLACSO, 2002.

OLIVEIRA, P. P. Discursos sobre masculinidade. Revista Estudos Feministas, Florianópolis, 1998, p. 91-113.

PÉREZ, Gonzalo. Masculinidades hegemónicas: trampas y resistencias al cambio. In: VALDÉS, Teresa y OLAVARRÍA, José (eds.). Masculinidades y equidad de género en América Latina. Santiago: FLACSO, 1998, p. 230 - 235.

PERLONGER, Néstor. O negócio do michê: a prostituição viril. São Paulo: Brasiliense, 1987.

PORTO, Rozeli. Gravidez e relações violentas: Representações de violência doméstica no municipio de Lages - SC. Dissertação de mestrado. PPGAS/UFSC, 2002. Acervo NIGS.

TARNOVSKI, Flávio Luiz. "Pais assumidos": Adoção e paternidade homossexual no Brasil Contemporâneo. Dissertação de mestrado. PPGAS/UFSC, 2002. Acervo NIGS.

VALDÉS, Teresa y OLAVARRÍA, José (eds.). Masculinidades y equidad de género en America Latina. Santiago: FLACSO, 1998. p. 207 - 217. 
VALE DE ALMEIDA, Miguel. Na companhia dos homens: sociabilidades masculinas. In: organizadores. Senhores de Si: uma interpretaçāo antropológica da masculinidade. Lisboa: Fim de Século, 1995. p. 181 - 210.

WELZER-LANG, Daniel. A construção do masculino: dominação das mulheres e homofobia, In: Revista Estudos Feministas, Florianópolis, vol. 09, n.02, 2001. p.460 482.

Dossiê PAGU masculinidades

Dossiê REF publicações feministas. 